\title{
INTRODUCING A COLLABORATIVE BUSINESS MODEL FOR EUROPEAN ERP VALUE CHAINS OF SMES
}

Ioannis Ignatiadis ${ }^{1}$, Jonathan Briggs ${ }^{1}$, Adomas Svirskas ${ }^{2}$, Kostas Bougiouklis $^{3}$, Adamantios Koumpis ${ }^{4}$

${ }^{\prime}$ Centre for Applied Research in Information Systems, Kingston University, UK \{I.Ignatiadis, J.H.Briggs\}@kingston.ac.uk

${ }^{2}$ Department of Computer Science, Vilnius University, LITHUANIA adomas@svirskas.com ${ }^{3} Q$-Plan North Greece, Thessaloniki, GREECE bougiouklis@qplan.gr

${ }^{4}$ Altec, Thessaloniki, GREECE akou@altec.gr

\begin{abstract}
Similarly to the high-end market segment, a large number of ERP installations in the small and medium market segments also fails or results in time and cost overnuns. To overcome those difficulties, a partnership-based e-business model amongst value chain actors is proposed. This model is supported by a platform, which engages and involves local actors in flexible multinational e-collaborations (forming European clusters in the ERP industry), in order to expand and broaden their activities. The envisaged outcome is to improve response times, low cost operations, flexibility towards clients, and provision of high-quality services tailored at end customers, facilitating the whole value chain to act as a single business entity (Virtual Organization).
\end{abstract}

\section{INTRODUCTION}

The European ERP market (which is a major part of ICT business applications market in Europe - worth approximately $€ 15$ billion) is dominated by large multinational actors, most of them outside the EU, focusing on high-end market segments (ERP solutions for large multinational companies). However, as the highend market has reached maturity, there is a shift of interest towards small and medium market segments (ERP solutions for small companies and SMEs). This market is currently open to European national large ERP vendors and/or SMEs, with a view to expanding in the future, also due to the enlargement of the EU.

A review (ALTEC-Corporation, 2004) of ERP installations in 3 European countries has in fact shown that more than $85 \%$ of ERP projects failed to complete in the assigned time period, whereas $60 \%$ of projects exceeded the initially planned costs.

In order to overcome those difficulties, a collaborative business model to facilitate interactions amongst players in the European ERP industry is proposed. Such players include ERP vendors, their national representatives, ERP dealers and consultants. The background of this paper is the EU co-funded project "PANDA" (PANDA-Project, 2006), currently in its implementation phase. PANDA's full title is "Collaborative Process Automation Support using Service Level Agreements and Intelligent Dynamic Agents in SME Clusters". This project aims to provide a

Ignatiadis, I., Briggs, J., Svirskas, A., Bougiouklis, K., Koumpis, A., 2007, in IFIP International Federation for Information Processing, Volume 243, Establishing the Foundation of Collaborative Networks; cds. Camarinha-Matos, L., Afsarmanesh, H., Novais, P., Analide, C.; (Boston: Springer), pp. 505-512. 
powerful framework of e-business services, dedicated to addressing current inefficiencies in the European ERP industry of SMEs, as well as facilitating international e-collaborations based on local actors and alliances. PANDA proposes the development of a new partnership based e-business model using the concept of RequestBased Virtual Organizations (RBVOs) (Roberts et al., 2005). PANDA also includes the development of a set of integrated supporting technologies in the form of a platform that will engage and involve local players in flexible multinational e-collaborations.

In the sections that follow, section 2 reviews relevant literature on the definition of e-business models, as well as e-collaboration. Section 3 introduces the proposed collaborative business model for European SME actors in the ERP industry, as exemplified through the PANDA project. Section 4 concludes this paper, by discussing other potential applications of the proposed collaborative model.

\section{2 \\ E-BUSINESS MODELS AND E-COLLABORATION}

\subsection{Business Model Definition}

Before discussing the proposed collaborative business model, it is first necessary to examine the definition of "business model". Although the concept of "business model" appeared for the first time in an academic article in 1957 (Bellman et al., 1957), its popularity grew only recently, in the end of the 1990s, mainly due to the increase of the e-business phenomenon. The number of times the term "business model" in fact appeared in the past in a business journal, seemed to trace the shape of the NASDAQ market index, potentially indicating the relationship of the term "business model" with technology (Osterwalder et al., 2005).

Nevertheless, there is still much disagreement, both in industry and in academia, on what constitutes a business model, and what its role and potential is. Osterwalder et al. notice that the term stands for many things, such as elements and relationships of a model, parts of a business model (e.g. auction model), concrete real world instances of business models (e.g. the Amazon model), or types of business models (e.g. business-to-business).

Several definitions of a business model have in fact been given in the literature, amongst which:

A description of the commercial relationship between a business enterprise and the products and/or services it provides in the market. (Hawkins, 2001)

An architecture of a firm and its network of partners for creating, marketing and delivering value and relationship capital to one or several segments of customers in order to generate profitable and sustainable revenue streams. (Pigneur, 2000)

An architecture for the product, service and information flows, including a description of the various business actors and their roles; and a description of the potential benefits for the various business actors; and a description of the sources of revenues. (Timmers, 1998) 
The business model presented in this paper is mainly concerned with defining the interactions and common processes amongst actors in European ERP value chains and the expected benefits to those actors, as exemplified by the real-world application of the PANDA project. The proposed business model is based on e-collaboration, which is presented next.

\section{$2.2 \quad$ E-Collaboration}

E-collaboration can be defined as business-to-business interactions among a group of collaborating parties, with the use of Information and Communication Technologies, particularly the Internet. Those interactions go beyond simple buy/sell transactions, and may be better described as relationships, including the sharing of resources amongst partners (Cheng et al., 2006; Johnson and Whang, 2002; Kock et al., 2001).

There are many driving forces behind e-collaboration. Companies are mainly driven by the increasing need of (i) information visibility and sharing along the supply chain, (ii) the efficient communication in a distributed network, (iii) the cost reduction and time compression philosophy, (iv) process automation, (v) increased potential opportunities of partnership, and (vi) the flexibility and adaptability. On the other hand, without the advances of enabling ICT technologies, all above could not be realistically achieved. Thus, the evolution of e-collaboration strongly depends on the developments and adoption of ICT technologies by both businesses and consumers.

E-collaboration tools have progressed from managing simple interactions among individuals to managing complex processes across entire supply chains. Collaboration in the supply chain has been widely discussed in the literature (e.g. Cassivi, 2006; Marquez et al., 2004; Ovalle and Marquez, 2003), and a wealth of concepts is at hand. The origin of supply chain collaboration could trace back to the emergence and promotion of supply chain management philosophy over the last decades, where it is realized that competition no longer takes place between individual businesses, but between entire supply chains. Collaboration can provide the competitive edge that enables all the business partners in the supply chain to act as one in order to achieve a synchronized and seamless supply chain.

Having described e-collaboration, the following section introduces the proposed e-collaboration model in the European ERP industry of SMEs.

\section{ONLINE COLLABORATION IN THE EUROPEAN ERP INDUSTRY INDUSTRY OF SMES}

Online collaboration for SME actors in the European ERP industry is exemplified through the PANDA project. Part of this project involves the development of a web platform, which is an enabler that helps the ERP actors to flexibly form and manage business relationships. The following sections discuss the target market of the proposed model, the key issues it tries to address and the differentiation of the model, the supported processes and comparison with traditional processes, as well as the innovation aspects associated with the online collaboration of ERP actors. 


\subsection{Target Market}

The proposed business model includes an advanced e-collaboration platform for actors in an ERP value chain (vendors, consultants, dealers, and national representatives), providing them with the capability to locate suitable partners across national boundaries, online manage running projects, and advertise their experiences and expertise. It goes a step ahead from simpler collaboration platforms, by automating many processes (such as searching for partners and monitoring progress) with the use of intelligent software agents (Multi-Agent System).

The platform is mainly addressed at serving large international or interregional ERP projects - demanding the cooperation of at least 2 different service providers e.g. 2 dealers, 1 national representative and 1 dealer, etc (and not ERP projects with narrow geographical spectrum or small budget - that can be fulfilled by only one dealer). Consequently, the platform focuses on ERP vendors' value chains at the small and medium market segment (ERP solutions for SMEs and/or Medium Enterprises or partially large). It does not envisage competing with large and well established multinational actors that are focusing on the high-end market segments (e.g. SAP, Microsoft, etc).

\subsection{Key Issues and Model Differentiation}

The problem that the proposed collaborative model tries to solve is associated with the limited partner networks in multinational e-collaborations, the lack of financial and human resources, the risk and uncertainty in expanding in new national markets, the lack of transparency regarding the availability of resources amongst collaborating partners, as well as the lack of expertise in addressing socio-economic barriers hindering internalization efforts. The impact of those is the difficulty in expanding activities the traditional way (e.g. establishment of branches in a foreign country).

Unlike networks having an own fixed, centrally supported, internationally-wide network of technical subsidiaries, the e-collaboration platform supporting the proposed business model in the European ERP industry of SMEs:

- Can be used by many value chains, supporting either an open source or proprietary product.

- Can be adapted to the particularities of each value chain (with regards to its structure, actor relationships, legal/financial/business issues).

- Is based on the notion of Request-Based Virtual Organizations (RBVOs) (Roberts et al., 2005), referring to a multinational cluster of ERP value chain actors, the cluster being formed ad-hoc upon a request from a value chain actor.

- Employs the use of sector-specific Service Level Agreements (SLAs), serving as the regulating framework of e-collaborations amongst RBVO members.

- Is served by a community of intelligent software agents (Multi-Agent System), developed to automate procedures and operations of RBVOs. Agents represent the intelligent 'back-office' of the platform, aiming at supporting interoperability, distributed peer to peer decision making, robustness, and knowledge sharing/private knowledge disclosure. 


\subsection{Supported Processes and Benefits}

The functionality of the platform to facilitate the envisaged collaborative model in the European ERP industry of SMEs was identified by interviewing actors (such as vendors, national representatives, dealers and consultants) in ERP value chains of European countries (such as Greece, Romania, Bulgaria, Germany, Hungary and Sweden). Most of the interviewed actors were active in their national markets for a number of years, and had an in depth knowledge of the business processes, practices and shortcomings, not only of their own value chain, but also of a large part of the ERP industry in their own and other European countries.

From the interaction with those actors the main requirements regarding the supported processes were elaborated. In general, the business model facilitated by the e-collaboration platform includes the following areas:

1. Pre-sales activity: formulation and submission of an offer to an end customer, providing necessary references, such as estimation of time schedule and cost, general conditions for project implementation, etc. This can be supported by data from the platform, e.g. using SLA templates to facilitate the (offline) negotiations with the customer. The benefit is the reduction in time and the standardisation in the submission of offers to customers according to pre-defined SLA templates.

2. Formation of consortium per ERP project: searching for potential partners based on a collaboration request, which incorporates major characteristics of the ERP project as well as specific conditions set by the client. This is supported by agent technologies using data from the platform such as partner reputation (see point 4 below), in order to identify the most suitable partners for a project. The benefit is the reduction in time and costs associated with manually identifying potential collaborators.

3. Overall monitoring/management of the consortium during implementation: including (if needed) re-planning of the project (e.g. changing tasks) and/or reconfiguration (e.g. adding or removing partners). This is supported by manual and automatic (agent) monitoring of the status of the project. The benefit is the flexibility and time savings in managing the running of the project.

4. Management of partner profiles: automatic update of the profiles of all partners-members of a project following project termination. This is supported by automatically recording project results and customer/partner feedback in the platform, which can include rating of partner performance. The benefit is the automatic archiving of the reputation of a partner in the platform, which can be used to measure the partner's suitability for participation in future collaborative projects.

Other benefits of the collaborative business model also include the expansion of geographical activities, as well as the building of new networks and strategic alliances with partners with complementary resources and expertise. Those new networks and strategic alliances can secure new projects for the firm, increasing its profit and market awareness, in its own or other countries. In addition, by using software agents throughout the life-cycle (i.e. partner selection, RBVO formation, 
operation and termination) of an RBVO associated with an ERP project, the relevant processes are automated, resulting in increased efficiency compared to the manual carrying out of those processes. The next section compares some of the traditional and online collaborative business processes.

\subsection{Comparison with Traditional Processes}

A comparison between the traditional and the processes associated with the proposed collaboration model is carried out in the table below.

Table 1 - Comparison of traditional and online collaborative processes

\begin{tabular}{|l|l|l|}
\hline Process & Current Solution & Online Collaboration \\
\hline $\begin{array}{l}\text { Partner } \\
\text { Identification }\end{array}$ & $\begin{array}{l}\text { Personal contacts } \\
\text { and } \\
\text { recommendations }\end{array}$ & $\begin{array}{l}\text { Automatic partner identification } \\
\text { (from pool of authorised companies) } \\
\text { by software agents. }\end{array}$ \\
\hline $\begin{array}{l}\text { Communication } \\
\text { of ERP } \\
\text { project's } \\
\text { requirements } \\
\text { and status }\end{array}$ & $\begin{array}{l}\text { Mostly by } \\
\text { telephone and e- } \\
\text { mail }\end{array}$ & $\begin{array}{l}\text { Holding of RBVO project data (pre, } \\
\text { during and post implementation) in } \\
\text { the platform's database, for viewing } \\
\text { and maintaining by authorised } \\
\text { partners. }\end{array}$ \\
\hline $\begin{array}{l}\text { Experience } \\
\text { sharing from } \\
\text { previous similar } \\
\text { ERP projects }\end{array}$ & $\begin{array}{l}\text { Mostly personal } \\
\text { contacts with } \\
\text { relevant actors }\end{array}$ & $\begin{array}{l}\text { Online archival of completed } \\
\text { projects, including solutions } \\
\text { provided, approaches and issues. }\end{array}$ \\
\hline $\begin{array}{l}\text { Contracting for } \\
\text { international } \\
\text { collaborations }\end{array}$ & $\begin{array}{l}\text { Ad-hoc formation } \\
\text { of contracts }\end{array}$ & $\begin{array}{l}\text { Storage of SLA templates in the } \\
\text { platform, used to guide negotiations } \\
\text { with the customer (pre-sales } \\
\text { activity), and/or potential partners. }\end{array}$ \\
\hline $\begin{array}{l}\text { Maintaining a } \\
\text { pool of partners }\end{array}$ & $\begin{array}{l}\text { Offline, or other } \\
\text { specialized } \\
\text { system (Excel, } \\
\text { CRM, etc) }\end{array}$ & $\begin{array}{l}\text { Online management (registration, } \\
\text { examination, reputation, etc) of } \\
\text { companies. }\end{array}$ \\
\hline
\end{tabular}

The major innovation aspects of the proposed online collaborative business model are summarized in the next section.

\subsection{Innovation Aspects}

Innovation in the proposed business model, as facilitated by the e-collaboration platform, lies in the combination of:

1. Process integration (enabled through innovative use of technologies, see point 4 below).

2. Increased business functionality and market responsiveness (through improved structural flexibility (RBVO) and business performance monitoring (SLAs)).

3. Collaborative actions enabled though improved coordination (RBVO model and agent technologies). 
4. Innovative use of technologies (such as agent technologies and ServiceOriented Architecture) through an integrated platform to support the collaborative value chain.

The combination of these factors (increased operational capability, tighter process integration coupled with business flexibility and a sound underpinning technical architecture/platform) provides the overall justification, if achieved, to claim that the proposed e-business model provides innovation, resulting in improved business performance (which in the future will be measured and evaluated).

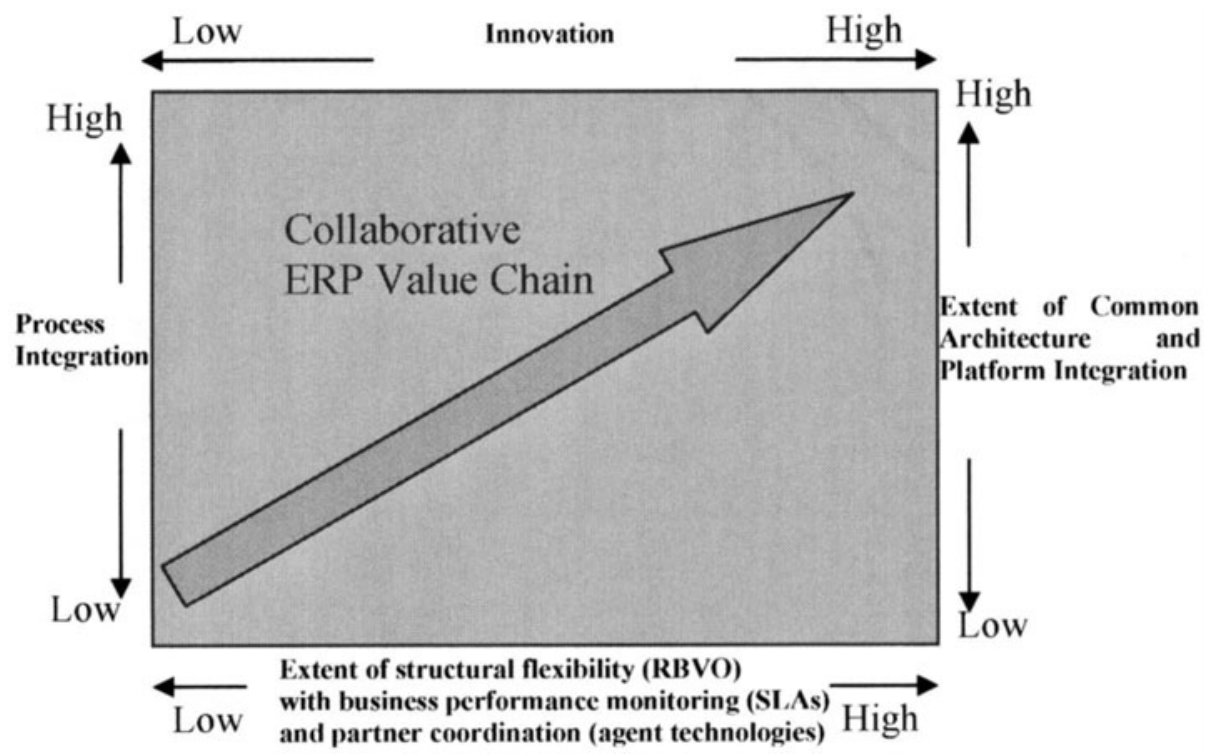

Figure 1 - Innovation aspects of the proposed e-collaboration model

\section{CONCLUSIONS}

The purpose of this paper has been to introduce a collaborative business model for the (European) ERP industry of SMEs, currently being implemented through the EU co-funded project "PANDA".

The duration of the PANDA project is 30 months, ending in summer 2008. The strategic impact of PANDA lies in its ambition to facilitate the creation of an efficient and integrated European industry on ERP systems. Although the PANDA project is exemplified in the European ERP industry for SMEs, the concepts, business and developed technological aspects could also be applied in other settings where collaborative projects are implemented. This includes practically any business sector where business-oriented software solutions (i.e. software products coupled with value added services to form 'extended' solutions) are used. As such, the 
PANDA project is important in serving as a demonstrator and proof-of-concept for future research and development in the area of collaborative e-business environments.

\section{ACKNOWLEDGEMENTS}

The authors would like to thank members of partner organisations from the PANDA consortium for their valuable input and help in developing the business model.

\section{REFERENCES}

1. ALTEC-Corporation. ERP Installations: Problems and Inefficiencies (Internal Company Report). 2004.

2. Bellman R, Clark CE, Malcolm DG, Craft CJ, Ricciardi FM. On the Construction of a Multi-Stage, Multi-Person Business Game. Operations Research 1957; 5: 469-503.

3. Cassivi L. Collaboration planning in a supply chain. Supply Chain Management 2006; 11: 249 - 258.

4. Cheng EWL, Love PED, Standing C, Ghavari H. Intention to e-collaborate: propagation of research propositions. Industrial Management \& Data Systems 2006; 106: 139-152.

5. Hawkins R. The "Business Model" as a Research Problem in Electronic Commerce. STAR (Socioeconomic Trends Assessment for the digital Revolution) IST Project, Issue Report No. 4, SPRU Science and Technology Policy Research, 2001.

6. Johnson ME, Whang S. E-business and Supply Chain Management: An Overview and Framework. Production and Operations management 2002; 11: 413-422.

7. Kock N, Davison R, Ocker R, Wazlawick R. E-collaboration: A look at past research and future challenges. Journal of Systems and Information Technology 2001; 5: 1-9.

8. Marquez AC, Bianchi C, Gupta JND. Operational and financial effectiveness of e-collaboration tools in supply chain integration. European Journal of Operational Research 2004; 159: 348-363.

9. Osterwalder A, Pigneur Y, Tucci CL. Clarifying Business Models: Origins, Present, and Future of the Concept. Communications of the AIS 2005; 15: 1-43.

10. Ovalle OR, Marquez AC. The effectiveness of using e-collaboration tools in the supply chain: an assessment study with system dynamics. Journal of Purchasing \& Supply Management 2003; 9: 151-163.

11. PANDA-Project. EU IST-027169. http://www.panda-project.com, 2006.

12. Pigneur Y. The E-business Model Handbook. HEC Working Paper 2000.

13. Roberts B, Svirskas A, Matthews B. "Request Based Virtual Organisations (RBVO): An Implementation Scenario". PRO-VE'05: 6th IFIP Working Conference on Virtual Enterprises, Valencia Spain, 2005.

14. Timmers P. Business Models for Electronic Markets. Electronic Markets 1998; 8: 3-8. 